\title{
Device-level vacuum packaged uncooled microbolometer on a polyimide substrate
}

\author{
Moinuddin Ahmed $^{\mathrm{a}}$, Donald P. Butler ${ }^{\mathrm{b}}$, and Zeynep Celik-Butler \\ ${ }^{a}$ University of Texas at Austin \\ Microelectronics Research Center \\ 10100 Burnet Rd. \\ Austin, TX 78758 \\ ${ }^{b}$ University of Texas at Arlington \\ Shimadzu Nanotechnology Center \\ Department of Electrical Engineering \\ 500 South Cooper Street \\ Arlington, TX 76019
}

\begin{abstract}
Uncooled infrared detectors (IR) on a polyimide substrate have been demonstrated where amorphous silicon (a-Si) was used as the thermometer material. New concepts in uncooled microbolometers were implemented during the design and fabrication, such as the integration of a germanium long-pass optical filter with the device-level vacuum package and a double layer absorber structure. Polyimide was used for this preliminary work towards vacuum-packaged flexible microbolometers. The detectors were fabricated utilizing a carrier wafer and low adhesion strength release layer to hold the flexible polyimide substrate during fabrication in order to increase the release yield. The IR detectors showed a maximum detectivity of $4.54 \times 10^{6}$
\end{abstract}


$\mathrm{cmHz}^{1 / 2} / \mathrm{W}$ at a $4 \mathrm{~Hz}$ chopper frequency and a minimum noise equivalent power (NEP) of 7.72 $\times 10^{-10} \mathrm{~W} / \mathrm{Hz}^{1 / 2}$ at a biasing power of $5.71 \mathrm{pW}$ measured over the infrared wavelength range of 8 $14 \mu \mathrm{m}$ for $35 \mu \mathrm{m} \times 35 \mu \mathrm{m}$ detector. These values are comparable to other flexible microbolometers with device-level vacuum packaging which are found in literature.

Keywords: Bolometer; flexible substrate; double layer absorber; optical filter; infrared radiation; MEMS sensors.

\section{Introduction}

Uncooled infrared detectors have been widely researched due to their lower operating cost and room temperature operation compared to their cryogenically cooled counterparts. The addition of self-packaging or device-level vacuum packaging technique where the chip package is fabricated with the detector across the wafer would help to reduce the cost of adding a separate conventional vacuum packaging to the devices $[1,2]$. Moreover, fabricating the detectors on flexible polyimide substrates helps the IR detector to conform to any non-planar surface such as a robot, night vision goggles, wearable electronic instrumentation, or other non-planar scientific instruments. All these features were utilized during design and fabrication of these IR detectors.

The resistance change of the detecting material with temperature due to the absorption of heat from infrared radiation was used to design the infrared microbolometers [3]. Depending on the material, the resistance may increase or decrease with temperature. There are a variety of materials that can be used as the sensor material or thermometer for room temperature detection 
of infrared radiation, such as $\mathrm{Y}-\mathrm{Ba}-\mathrm{Cu}-\mathrm{O}$ [1], $\mathrm{SiGe}$ [4], amorphous $\mathrm{Si}$ (a-Si) [5], polysilicon [6], and $\mathrm{VO}_{\mathrm{x}}$ [7]. The selection of the material depends on the compatibility of the fabrication process, sensitivity of the material with temperature variation, noise floor, and operating temperature. We previously utilized a-Si as a sensing material for temperature sensors which showed low 1/f-noise [8] and a temperature coefficient of resistance (TCR) of $-2.88 \% / \mathrm{K}$ [9]. For the current work, a-Si was used as the detecting material $[10,11]$ and served as a test bed to prove several concepts that we developed during the microbolometer design while, at the same time, focusing on achieving comparable performance with the flexible microbolometer counterparts.

There were two concepts we worked to implement during fabrication of the detectors. The incorporation of a long-pass optical filter with the device-level vacuum package and a double layer absorption structure to allow control over the infrared radiation absorption bandwidth during the design phase. The implementation of device-level vacuum packaging with an integrated optical filter is essential to the development of practical flexible microbolometers. The details of the design and simulation results, as well as, some preliminary work can be found in our earlier publication [12]. Germanium has a high extinction coefficient in visible wavelength range and low extinction coefficient for sub-optical-bandgap radiation [13, 14], which means that a germanium long-pass filter will block visible light while allowing the long-wave infrared radiation to reach the detector. Ge is commonly used for long-wave infrared optics. The Ge filter was integrated with the device-level vacuum package providing both optical filtering function while increasing the mechanical strength of the vacuum package. In the current work, the a-Si detecting material was sandwiched between a top and a bottom electrode which both absorbed the IR radiation and transferred the heat to the detecting material, thereby creating a double layer 
absorber structure. The thickness of different layers was optimized through Monte-Carlo simulation so that the maximum absorption takes place on the electrodes in a wavelength range of 8-14 $\mu \mathrm{m}$. The integration of the optical filter during the device fabrication would reduce the cost of adding additional external filters to the system.

In addition to those features, the microbolometers on polyimide were fabricated utilizing a new release layer technology as discussed by Ahmed et al. [15] in order to avoid any unwanted destruction of the detectors during the release from the silicon carrier wafer. Though, in this preliminary work, the detectors were characterized before releasing the flexible substrate (holding the detectors) from silicon carrier wafer. Our preliminary results were presented in [16].

\section{Experimental Details}

\subsection{Fabrication of the bolometers on the flexible substrate}

The visual representation of the cross-sectional view, step-by-step fabrication process and top view of detecting part are illustrated in Fig. 1, Fig. 2 and Fig. 3 respectively. Most of the depositions were done by rf magnetron sputtering in an Ar-gas environment. The fabrication starts with growth of the flexible substrate on the silicon carrier wafer. For this purpose, the $\mathrm{Si}_{3} \mathrm{~N}_{4}$-PI2611 (release layer)-PI5878G (flexible substrate)- $\mathrm{Si}_{3} \mathrm{~N}_{4}$ layers were deposited to facilitate fabrication of the sensors and their easy removal from the flexible substrate after fabrication (details are discussed in [15]). The thickness of the PI5878G polyimide substrate 
layer was $70 \mu \mathrm{m}$. The top $\mathrm{Si}_{3} \mathrm{~N}_{4}$ passivation layer defines the device plane. First, a 303-nm-thick aluminum mirror layer was sputtered onto the passivation layer and patterned through lift-off process to form reflecting mirrors. Later, thinned HD4104 was spin-coated, patterned and cured at $250{ }^{\circ} \mathrm{C}$ to get a final thickness of $548 \mathrm{~nm}$ which was named as the thin sacrificial layer. Next, HD4104 was deposited and patterned on top of the thin sacrificial layer. It was cured at $250{ }^{\circ} \mathrm{C}$ to achieve a final thickness of $3.2 \mu \mathrm{m}$ to form a thick sacrificial layer. On top of the sacrificial layers a 109 -nm-thick alumina $\left(\mathrm{Al}_{2} \mathrm{O}_{3}\right)$ layer was sputtered and patterned through lift-off process to form the base membrane for the thermometer. After that, a metallization layer was formed by sputtering a 130-nm-thick nichrome (Ni 80\%-Cr 20\%) film and patterned to connect the bottomelectrode to the bond pads. The thin nichrome layer of metallization also served to reduce the thermal conductance from the thermometer to the substrate. Then, a 32-nm-thick aluminum film was sputtered and patterned by lift-off to create the bottom electrode. On top it, an a-Si (500$\mathrm{nm})$-aluminum (30-nm)-alumina (20-nm) tri-layer was deposited and patterned by simultaneous lift-off. The a-Si acts as the sensing material or thermometer; where the aluminum acts as the top electrode and absorber for the infrared radiation. The aluminum also prevents oxidation of silicon [9]. The alumina protects the top electrode from oxidation during the surface micromachining process. Later, HD4104 polyimide was spin-coated, patterned by photolithography and cured at $250{ }^{\circ} \mathrm{C}$ to achieve a final thickness of $3.2 \mu \mathrm{m}$. This polyimide served as the top sacrificial layer to create a vacuum cavity between thermometer and the subsequent encapsulation layer. Then, a 558-nm-thick alumina, encapsulation layer was sputtered onto the sacrificial layer and patterned by lift-off process. This layer contained etch holes to aid the removal of the polyimide sacrificial layers by surface micromachining. After that, all three layers of sacrificial polyimides were removed by a Plasma Therm asher. This 
process created a cavity below and above the thermometer to form a thermally isolated structure. Then, the etch holes of the encapsulation layer were sealed with a 2- $\mu$ m-thick $\mathrm{Al}_{2} \mathrm{O}_{3}$ packaging layer which also covered the bond pads. Here, the thin sacrificial layer helped to decrease the necessity of a thicker packaging layer by forming a small gap between passivation layer and encapsulation layer. Next, the bond pads were opened through wet etching in phosphoric acid. Then, Ge optical filter of thickness 720-nm was thermally evaporated on the detector; followed by the lift-off process to pattern the filter (Fig. 4). After that, HD4110 was spin-coated, patterned by photolithography and cured at $250{ }^{\circ} \mathrm{C}$ to obtain a final of thickness of $47 \mu \mathrm{m}$ (Fig. 5). This final polyimide served as a superstrate layer for the detectors to keep them at a low stress plane. A $1 \mathrm{~cm} \times 1 \mathrm{~cm}$ piece of flexible substrate which contains 14 microbolometers (Fig. 6) was removed from silicon carrier wafer to check the performance of the low adhesion strength release layer [15] after the multi-layer processing. The flexible substrate could be easily removed. Though, the sensors that were characterized remained on the silicon carrier wafer in this preliminary work using a custom built IR probe station.

\subsection{Microbolometer resistance measurement}

The first stage of the characterization was to measure the resistance values of the microbolometers. Each detector had two resistors: one surface micromachined resistor for detecting infrared radiation (microbolometer) which is termed as the active resistor $\left(\mathrm{R}_{\mathrm{a}}\right)$ and the other resistor on top of the substrate which is termed as the passive resistor $\left(\mathrm{R}_{\mathrm{p}}\right)$ or reference resistor. The purpose of the passive resistor was to subtract the effect of room temperature variations and the absorption of visible light from microbolometer response. The resistance was 
measured by using a semiconductor parameter analyzer (HP 4155C) to measure the I-V characteristic of each resistor individually. The slope of the I-V curve gave resistance values of each resistor.

\subsection{IR Characterization}

The flexible microbolometers, attached to the silicon carrier wafer, were characterized by probe testing with IR illumination of detectors. To characterize the sensors on the silicon carrier wafer the wafer was placed horizontally on a flat surface. Its bond pads were probed and the wafer was illuminated by filtered IR radiation from above. In order to facilitate this testing, an IR probe station was built.

\subsubsection{IR probe station}

The IR probe station was built on an optical bench. The detectors on the wafer were probed and an IR source was projected vertically on the detectors. For that purpose a quartz tungsten halogen lamp (operated at $90 \mathrm{~W}, 0.8 \mathrm{~A}$ ) was placed as the source with a $\mathrm{ZnSe}$ condenser. A chopper wheel was set to modulate radiation at a desired frequency. In order to limit the wavelength range from the IR source, a long pass optical filter $(5100 \mathrm{~nm})$ was placed into the optical path. A ZnSe lens was used to focus the IR radiation on the detector under test. The ZnSe provided the long wave cutoff of the IR radiation at approximately $13,000 \mathrm{~nm}$. In order to check the irradiance of the IR source, the same setup was moved by $90^{\circ}$ and a reference pyroelectric detector was place instead of the detector under test. The setup is shown in Fig. 7. 


\subsubsection{IR response and noise characterization of the bolometers}

After placing wafer on the optical bench and illuminating IR onto the test detector, a dc bias voltage was applied across the bolometer and the reference resistor as shown in Fig. 8. The chopper frequency was set to a particular frequency. The output voltage of the bolometer was fed to a pre-amplifier which was set in differential mode with a voltage gain of 100 . The output signal from the pre-amplifier was then connected to HP3562A dynamic signal analyzer to record detector's rms output voltage and the noise voltage power spectral density in frequency domain, after averaging each measurement 10 times. The bias voltage for any particular measurement was varied from $\pm 0.5 \mathrm{~V}$ to $\pm 1.25 \mathrm{~V}$ in step of $0.25 \mathrm{~V}$ while keeping the chopper frequency constant. After that, the chopper frequency was varied from $4 \mathrm{~Hz}$ to $200 \mathrm{~Hz}$ while keeping bias voltage fixed. A photo-diode was used to record the variation of IR source intensity with time.

For each measurement described above, at a particular bias voltage and particular chopper frequency, the noise voltage power spectral density was recorded in the frequency range of 10 to $1000 \mathrm{~Hz}$ with and without IR illumination in order to measure the 1/f noise [17], after subtracting background noise [18].

\section{Results and Discussions}

From the slope of output I-V relationship for the active resistor and passive resistors, the corresponding resistance values of individual resistors were calculated. 
Table 1 shows the resistance values for the fabricated microbolometers that were characterized for IR response. It could be observed here that there is a large variation of resistance values for pixels of same area. The non-uniformity of the thickness of the sensing material over the large wafer area, lithographic misalignment of the bottom electrode and detector, oxidation of the electrodes and a-Si thermometer around the periphery during surface micromachining could cause such variation of the resistance.

Representative signal spectra for a detector that was illuminated with infrared radiation at a chopper frequency of $40 \mathrm{~Hz}$, causing the thermometer resistance to change at that frequency and producing a corresponding output voltage signal across the detector are shown in Fig. 9. The peak in the output voltage versus frequency spectra at the chopper frequency reflects the detection of the IR radiation by the detector. The corresponding noise voltage power spectral density was also recorded over the same frequency range as shown in Fig. 9 (inset) after dividing by the gain of the pre-amplifier. The input bias voltage was set at $\pm 1 \mathrm{~V}$ and the detector is named as 60TL_6x6. The peak root-mean-square voltage was found to be $1.54 \times 10^{-4} \mathrm{~V}$ and noise voltage PSD was recorded as $5.54 \times 10^{-11} \mathrm{~V}^{2} / \mathrm{Hz}$ at $\sim 40 \mathrm{~Hz}$ chopper frequency.

Once the microbolometer was illuminated with IR radiation without any chopper modulation, the noise voltage PSD was recorded over the frequency range of 10 to $1000 \mathrm{~Hz}$. The noise voltage PSD after subtracting from background noise, with and without presence of infrared radiation is shown in Fig. 10 (for the detector termed as 60TL_6x6). It is obvious here that, with infrared radiation, detector showed almost similar 1/f noise PSD. The noise voltage 
PSD demonstrated quadratic variation with input bias voltage [Fig. 10 (inset)] for the detector termed as 60TL_7x9 which was used to calculate normalized 1/f noise Hooge coefficient. The Hooge coefficient was found to be $1.21 \times 10^{-13}$ at bias voltage of $\pm 1 \mathrm{~V}$.

\section{Figure of Merits}

Responsivity defines the variation of the output signal (voltage here) of the detector in response to the input signal (radiant flux here). The responsivity for the bolometer can be defined as, $R_{v}$ [19]:

$$
R_{v}=\frac{V}{\phi}
$$

Where $\mathrm{V}$ is the output voltage variation across the detector and $\Phi$ is the radiant flux incident on the bolometer. The radiant flux was measured from the irradiance of the infrared source by using a reference detector and the area of the particular bolometer.

The responsivity of the detectors at various chopper frequency is shown in Fig. 11 while keeping the bias voltage constant. The reduction in responsivity after a particular chopper frequency reflects the thermal cut-off frequency effect of the device. For instance, the cut-off frequency of the designed 60TL_6x6 detector was $113.25 \mathrm{~Hz}$, which demonstrated significant decrease in responsivity after $100 \mathrm{~Hz}$, for the detector termed as $60 \mathrm{BL} \_5 \times 2$ showed a reduction after $80 \mathrm{~Hz}$. The longer the surface micromachined legs become, the cut-off frequency becomes shorter. The variation of the responsivity with the change of bias voltage showed a linear increase in responsivity at fixed chopper frequency of $40 \mathrm{~Hz}$ as shown in Fig. 12 (inset) (detector 60 BL_5x2). The increment of bias voltage has a negative effect on the detector since it causes 
break down of the detector (above $\pm 1.25 \mathrm{~V}$ ). So the characterization was performed within this limit of bias voltage.

The area normalized signal to noise ratio is termed as the detectivity, $D^{*}[19]$ of sensor which is expressed as:

$$
D^{*}=\frac{R_{v} \sqrt{A_{d} \Delta f}}{V_{n}}
$$

Where $V_{n}$ is the noise voltage of the detector over the frequency bandwidth of $\Delta \mathrm{f}$ which has detecting area of $A_{d}$.

In Fig. 12, the variation of detectivity with the increase of frequency from $4 \mathrm{~Hz}$ to $200 \mathrm{~Hz}$ showed that no significant change occurred. Note that, this reflects the chopper test frequency was below the designed cut-off frequency of the detector. The bias voltage was fixed at $\pm 1 \mathrm{~V}$. On the contrary, the detectivity showed [Fig. 12 (inset)] an increase with the variation of input bias voltage while the chopper frequency was kept constant at $40 \mathrm{~Hz}$. The nature of the variation of the detectivity with the variation of bias voltage was beyond the experimental limits due to the aSi break down voltage.

The noise equivalent power, NEP [19] of a detector is the incident radiant power which produces a SNR of 1, and expressed as:

$$
N E P=\frac{\sqrt{A_{d} \Delta f}}{D^{*}}
$$

The change in NEP with the frequency variation from $4 \mathrm{~Hz}$ to $200 \mathrm{~Hz}$ could be observed in Fig. 13 which demonstrates the sudden increment of NEP after the cut-off frequency at a fixed bias. While the change of NEP with bias voltage follows the opposite trend [Fig. 13 (inset)], 
which showed the decrease in NEP with the increase of bias voltage at a fixed chopper frequency. The slope of NEP with respect to bias voltage decreases The summary of the measured responsivity, detectivity and NEP is represented in Table I.

Even though the detectivity is area normalized; but it was observed (Table I) the detectivity of $35 \mu \mathrm{m} \times 35 \mu \mathrm{m}$ (pixel size) is higher than those of $60 \mu \mathrm{m} \times 60 \mu \mathrm{m}$ detector. There could be two reasons for such variation. One is there might be some debris of polyimide left below the membrane of the $60 \mu \mathrm{m} \times 60 \mu \mathrm{m}$ detector. Since there were three layers of polyimide and etch hole around the edge of membrane were the only way to reach the polyimide by the etchant molecules. If the area of the detector goes high, the chance of debris to leave behind always go higher. The presence of debris reduces the effective absorption of radiation by the detecting material, taking into consideration that the detector were designed to absorb maximum radiation near the detecting material. Second reason is that the some polyimide might have left below the membrane which conducts heat from the detector to the substrate. The second reason is less convincing, because the presence of a thermally conducting path would also have affected the cut-off frequency.

In order to avoid these affects, a longer micromachining steps would have been useful to completely remove debris of polyimide below the detector. But it was observed that longer micromachining created stress on the gold bond pads which caused removal of the bond pads. In order to avoid the bond pad etching, an additional alumina layer could be deposited on top of the gold. There was a step of bond pad opening for vias, so depositing alumina will not increase the fabrication steps or complexity. 
The current results were compared to some of the earlier works done by Mahmood et al.[1] and Dayeh et al.[20] in Table 2. It should be noted that the flexible microbolometers in Dayeh et al. were not device-level vacuum packaged. The maximum responsivity is comparable to the earlier works, the NEP is lower while the current detector requires lower biasing power. This is advantageous for this detectors, since they are equipped with the self-packaged long-pass germanium filter which eventually blocks visible light. Another important finding is that, the concept of double layer absorber worked for these detectors while maintaining performance with their counterparts. The maximum detectivity was found to be $4.54 \times 10^{6} \mathrm{cmHz}^{1 / 2} / \mathrm{W}$ at $4 \mathrm{~Hz}$ while NEP was calculated as $7.72 \times 10^{-10} \mathrm{~V} / \mathrm{Hz}^{1 / 2}$ at $4 \mathrm{~Hz}$ for for $35 \mu \mathrm{m} \times 35 \mu \mathrm{m}$ detector. The low extinction coefficient of $\mathrm{Al}_{2} \mathrm{O}_{3}$ in the visible light spectrum as well as the infrared wavelength range allowed it to become a suitable candidate as a packaging layer; which means the addition of a packaging layer does not contribute towards reducing bolometer's performance significantly. In the simulations, it was observed that, due to the addition of the germanium layer, the absorption spectra was tuned to $11.5 \mu \mathrm{m}$ with a narrow spectral response in the $8-14 \mu \mathrm{m}$ band compared to a wide spectral response without any germanium optical filter. Narrowing of the detector's spectral response compared to the broad band radiation used to measure the responsivity and detectivity is likely, at least in part, responsible for the comparatively low responsivity and detectivity measured.

This work demonstrates that device-level vacuum packaged microbolometers with a double layer absorption structure can be fabricated on flexible polyimide, based on our previous design and simulation [12]. We have utilized a-Si as a sensing material, but the design is open to 
any other types of resistive bolometer materials or even pyroelectric materials; which will require the reoptimization of layer thicknesses for maximum absorption of detector. Since the detector was built on a flexible polyimide substrate, we envision the application the detectors to curved, non-planar surfaces with a constant strain. If the strain on the detector resistor and reference resistor changed, piezoresistivity or piezoelectricity of these materials may require recalibration of the detectors. a-Si for example displays a piezoresistive effect. a-Si microbolometers with conventional vacuum packaging [3] have been demonstrated with higher detectivity. Simulations indicate higher performance is potentially available for device-level vacuum packaged microbolometers as well, but the fabrication process needs further improvement to fully realize the potential performance.

\section{Conclusions}

Microbolometers inside a flexible polyimide substrate have been fabricated and characterized. The wavelength range of interest was $8-14 \mu \mathrm{m}$. For this purpose, amorphous silicon was used as a detecting or thermometer material which was sandwiched between Al electrodes that also served as the absorber materials. The entire detector was device-level vacuum packaged using an alumina packaging layer. In addition to it, an optical long-pass filter was incorporated with the detector in order to absorb the visible light before it reaches the microbolometer. The IR detectors showed a maximum detectivity of $4.53 \times 10^{6} \mathrm{cmHz}^{1 / 2} / \mathrm{W}$ at $4 \mathrm{~Hz}$ of chopper frequency, minimum noise equivalent power $(\mathrm{NEP})$ of $7.72 \times 10^{-10} \mathrm{~W} / \mathrm{Hz}^{1 / 2}$ at a biasing power of $5.71 \mathrm{pW}$. These microbolometers showed improved performance compared to their device-level vacuum packaged flexible counterparts that did not utilize an integrated optical filter. 


\section{Acknowledgements}

This work was supported in part by the National Science Foundation under Grant IIS-120862.

[1] A. Mahmood, D. P. Butler and Z. Celik-Butler, A device level vacuum packaging scheme for microbolometers on rigid and flexible substrate, IEEE Sens. J. 7 (7) (2007) 1012-1019.

[2] M. Shahriar Rahman, Murali Chitteboyina, Donald P. Butler, Zeynep Celik-Butler, Sergio Pacheco, and Ronald McBean, Device-level vacuum packaged MEMS resonator, IEEE/ASME Journal of Microelectromechanical Systems, 19 (4) (2010) 911-917.

[3] A. Rogalski, Infrared detector: An overview, Infrared Phys. \& Technol, 43 (2002) 187-210.

[4] M. M. Rana, D. P. Butler, "High responsivity a- $\mathrm{Si}_{\mathrm{x}} \mathrm{Ge}_{1 \mathrm{x}} \mathrm{O}_{\mathrm{y}}: \mathrm{H}$ microbolometers," IEEE Sens. J., 7 (10) (2007) 1413-1419.

[5] R. Ambrosio, M. Moreno, J. Mireles, A. Torres, A. Kosarev and A. Heredia, An overview of uncooled infrared sensors technology based on amorphous silicon and silicon germanium alloys, Phys. Status Solidi C, 7 (3-4) (2010) 1180-1183.

[6] E. Obermeier and P. Kopystynski, Polysilicon as a material for microsensor applications, Sensors and Actuators A, 30 (1-2) (1992) 149-155.

[7] F. J. Gonzalez, M. Abdel-Rahman and G. D. Boreman, Antenna-coupled VOx thin-film microbolometer array, Microwave and Optical Tech. Letts., 38 (3) (2003) 235-237.

[8] M. Ahmed, D. P. Butler, Z. Celik-Butler, The flicker noise in amorphous silicon based temperature sensors in flexible substrates, Proc. ICNF, (2011) 154-157.

[9] M. Ahmed, M. M.Chitteboyina, D. P. Butler and Z. Celik-Butler, Temperature sensor in a flexible substrate, IEEE Sensors J., 12 (5) (2012) 864-869.

[10] X. M. Liu, L. Han, L. T. Liu, A novel uncooled a-Si microbolometer for infrared detection, Proc. ICSICT, (2006) 626-628.

[11] X. M. Liu, H. J. Fang, L. T. Liu, Study on new structure uncooled a-Si microbolometer for infrared detection, Microelectronics J., 38 (2007) 735-739.

[12] M. Ahmed, D. P. Butler, Design and simulation of device-level vacuum packaged microbolometer with integrated optical filter, IEEE Sensor J., 15 (12) (2015) 6986 - 6994. 
[13] H. Rafla-Yuan, J. D. Rancourt and M. j. Cumbo, Ellipsometric study of thermally evaporated germanium thin film, Appl. Optics, 36 (25) (1997) 6360-6363.

[14] Tydex Optics, Inc, Optics for sensors and detectors or Germanium [Online], Available:http://www.tydexoptics.com

[15] M. Ahmed and D. P. Butler, Flexible substrate and release layer for flexible MEMS devices, J. Vac. Sci. Technol. Lett., 31 (5) (2013) 050602-050602-4.

[16] M. Ahmed, D. P. Butler, and Z. Celik-Butler, Low-Profile, Self-Packaged, Uncooled Microbolometer on a Flexible Substrate towards an Infrared Radiation Sensitive Skin, Proc. IEEE Sensors, (2014) 2155-2158.

[17] F. N. Hooge, T. G. M. Kleinpenning and L. K. J. Vandamme, Experimental studies on 1/f noise, Rep. Prog. Phys., 44 (1981), 479-532.

[18] Z. Celik-Butler, 1/f Noise in Semiconductor Devices, Ph.D, Thesis, University of Rochester, 1987.

[19] E. L. Dereniak, and G. D. Boreman, "Optical-detection processes, in Infrared detectors and systems, $1^{\text {st }}$ ed., New York: John Wiley \& Sons, Inc, 1996, ch. 3, sec. 3.1-3.3, pp. 86123.

[20] S. A. Dayeh, D. P. Butler, and Z. Celik-Butler, Micromachined infrared bolometers on flexible polyimide substrates, Sensors and Actuators A: Phys., 118 (1) (2005) 49-56.

Figure captions

Fig. 1: Cross-sectional view of the surface micromachined bolometer showing different layers and cavity (dimensions are not scaled according to the actual dimension); cavity was created by etching sacrificial layers.

Fig. 2: Step by step fabrication process of a micromachined microbolometer on a flexible substrate with an integrated vacuum cavity.

Fig. 3: CoventorWare model of one detector showing the pixel connected with substrate through the metallization layer 
Fig. 4: Confocal microscope image of the fabricated microbolometer showing micromachined microbolometer and reference resistor covered with the germanium long-pass filter.

Fig. 5: SEM micrograph of packaged bolometer surrounded by top the superstrate polyimide layer around the periphery

Fig. 6: A $1 \mathrm{~cm} \times 1 \mathrm{~cm}$ piece of flexible substrate containing 14 micromachined microbolometers with reference resistors.

Fig. 7: Set-up of the IR probe station on the optical bench for testing the microbolometers under IR radiation and recording the output voltage and the noise voltage power spectral density.

Fig. 8: Electrical connection of the microbolometer with the battery driven power source and output signal analyzer.

Fig. 9: Output voltage as function of frequency when chopper was set at $40 \mathrm{~Hz}$ for a $60 \mu \mathrm{m} \times 60$ $\mu \mathrm{m}$ detector. (inset) Output voltage noise power spectral density for the same set-up.

Fig. 10: Noise voltage power spectral density of a $60 \mu \mathrm{m} \times 60 \mu \mathrm{m}$ detector with frequency. (inset) showing variation of noise voltage power spectral density with input bias voltage (for the noise voltage PSD recorded at $10 \mathrm{~Hz}$.

Fig. 11: Responsivity as a function of chopper frequency at a input bias voltage of $\pm 1 \mathrm{~V}$ for 60 $\mu \mathrm{m} \times 60 \mu \mathrm{m}$ pixel. (inset) showing change responsivity with input bias voltage at a fixed chopper frequency of $40 \mathrm{~Hz}$.

Fig. 12: Variation of detectivity with chopper frequency for $35 \mu \mathrm{m} \times 35 \mu \mathrm{m}$ detector at $\pm 1 \mathrm{~V}$ input bias voltage. (inset) showing the variation of NEP with bias voltage at a chopper frequency of $40 \mathrm{~Hz}$.

Fig. 13: NEP of a $60 \mu \mathrm{m} \times 60 \mu \mathrm{m}$ with the variation of chopper frequency at $\pm 1 \mathrm{~V}$ input bias voltage. (inset) showing the variation of NEP with the input bias voltage at a chopper frequency 
of $40 \mathrm{~Hz}$.

Table caption

Table 1: Summary of the characteristics of the bolometers.

Table 2: Comparison of figures of merit. 
Figure 1

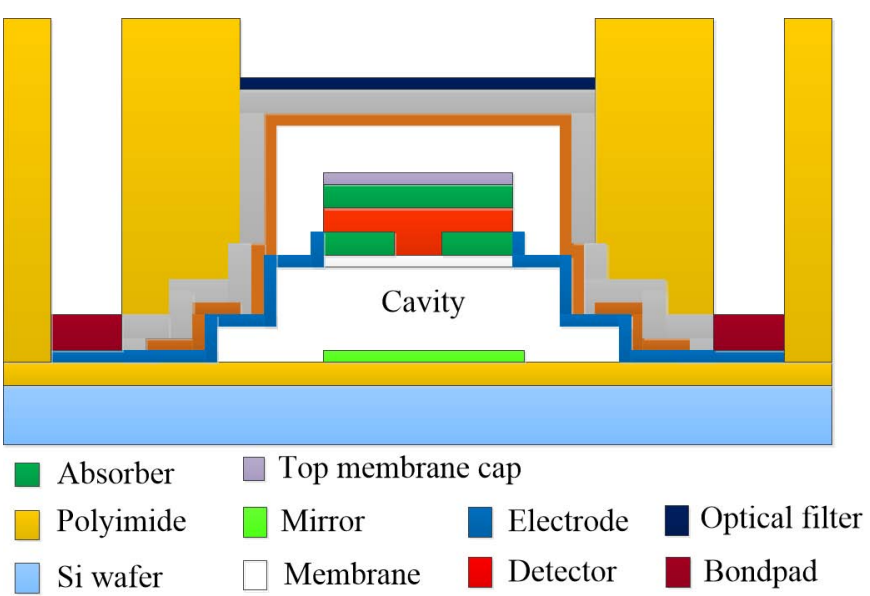

Metallization layer $\square$ Encapsulation layer $\square$ Packaging layer 
Figure 2

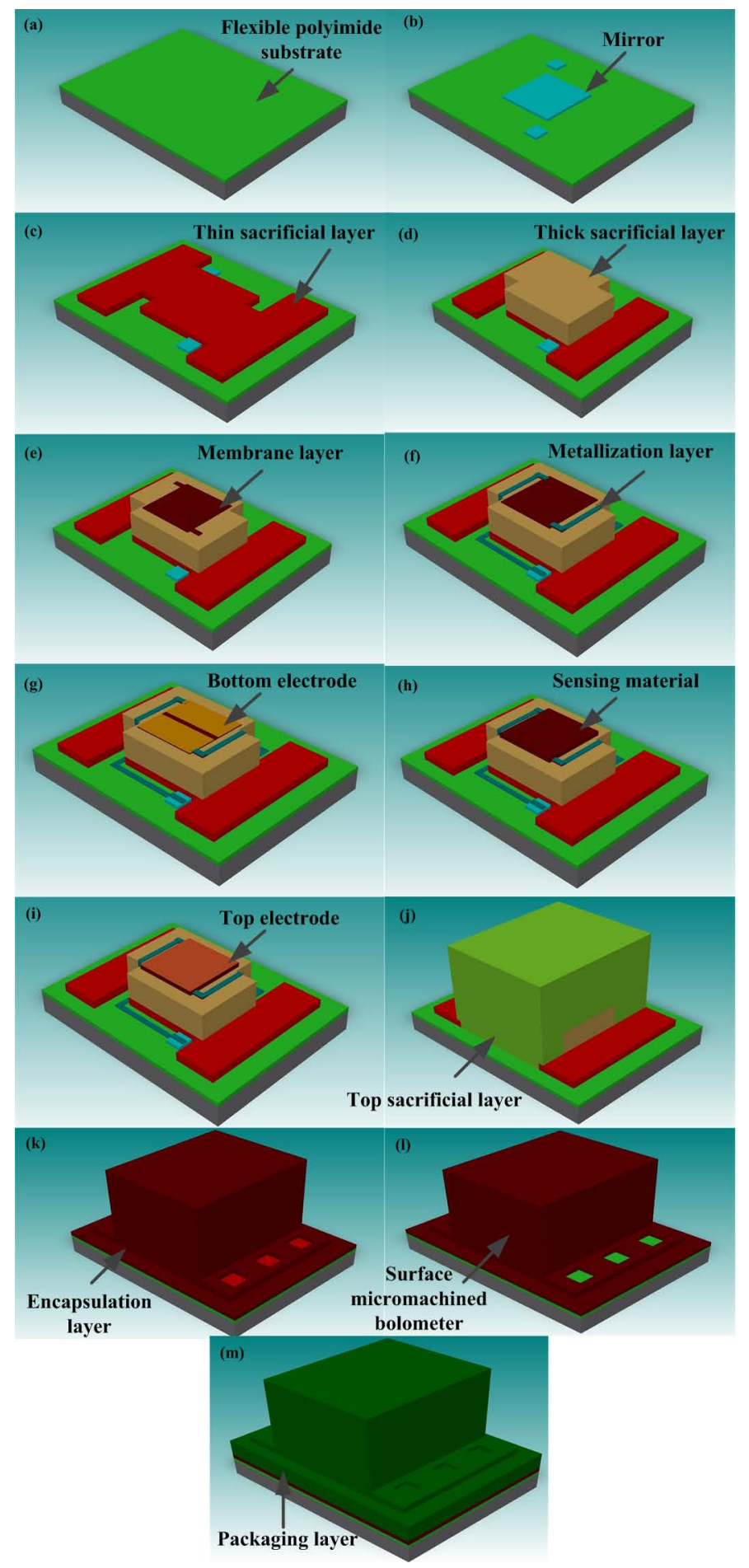


Figure 3

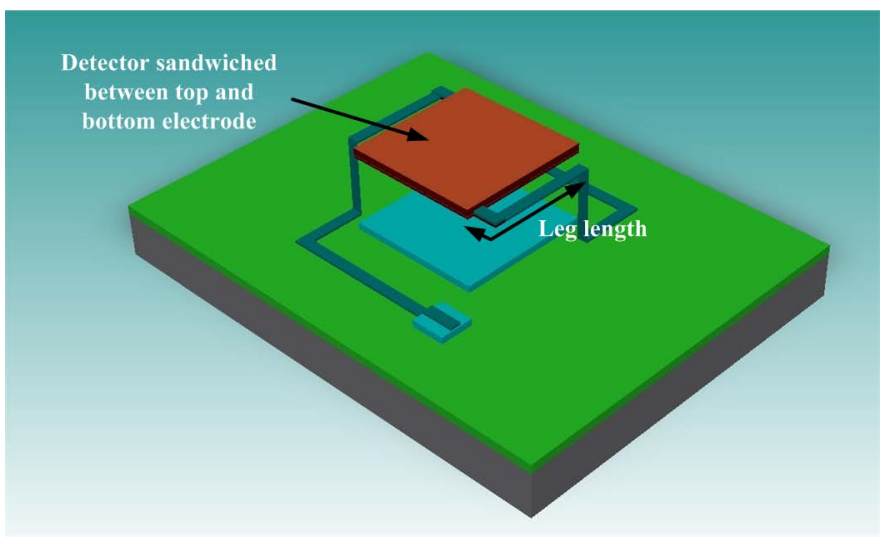


Figure 4

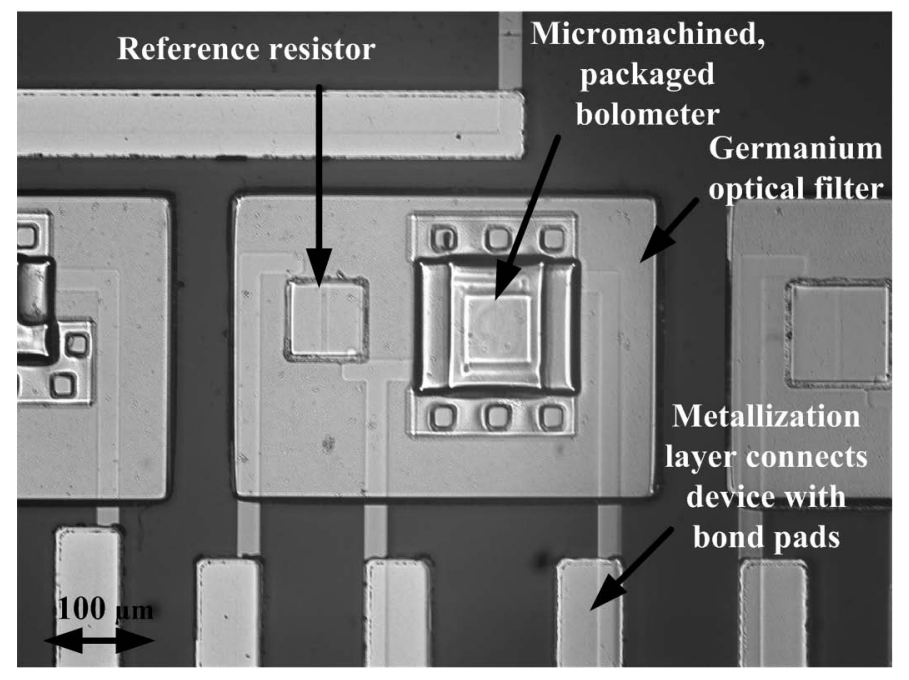


Figure 5

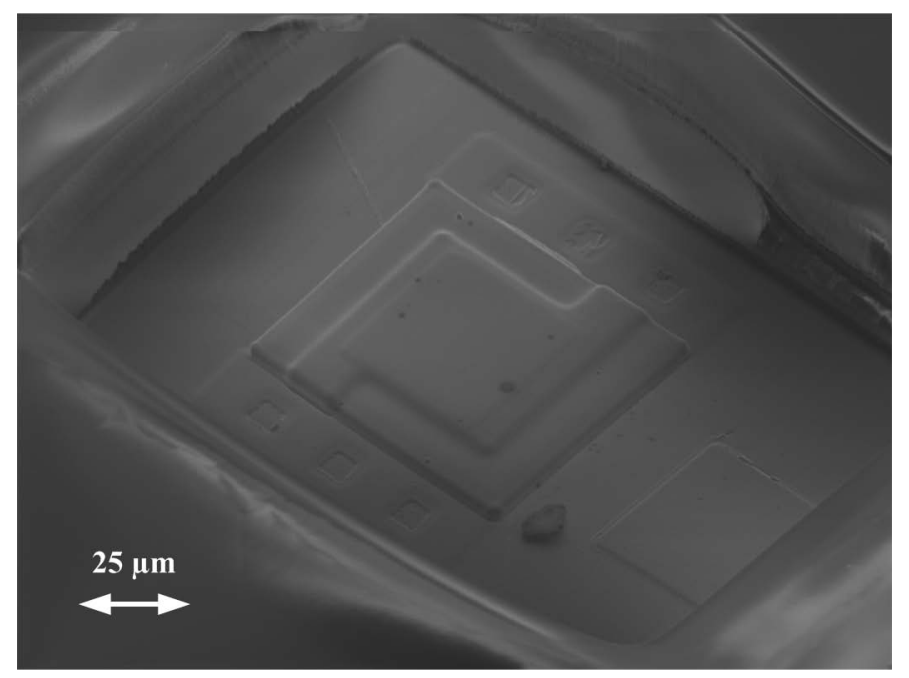


Figure 6

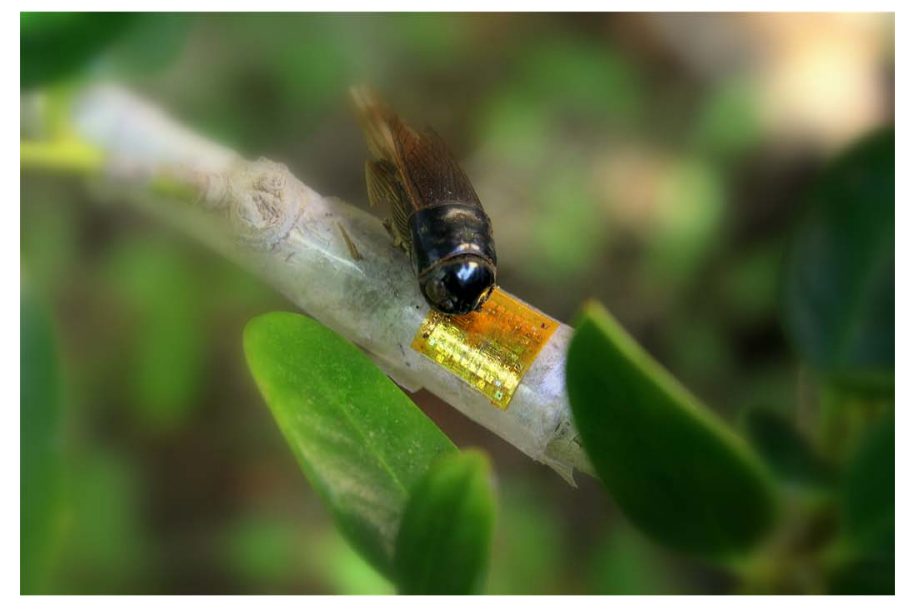


Figure 7

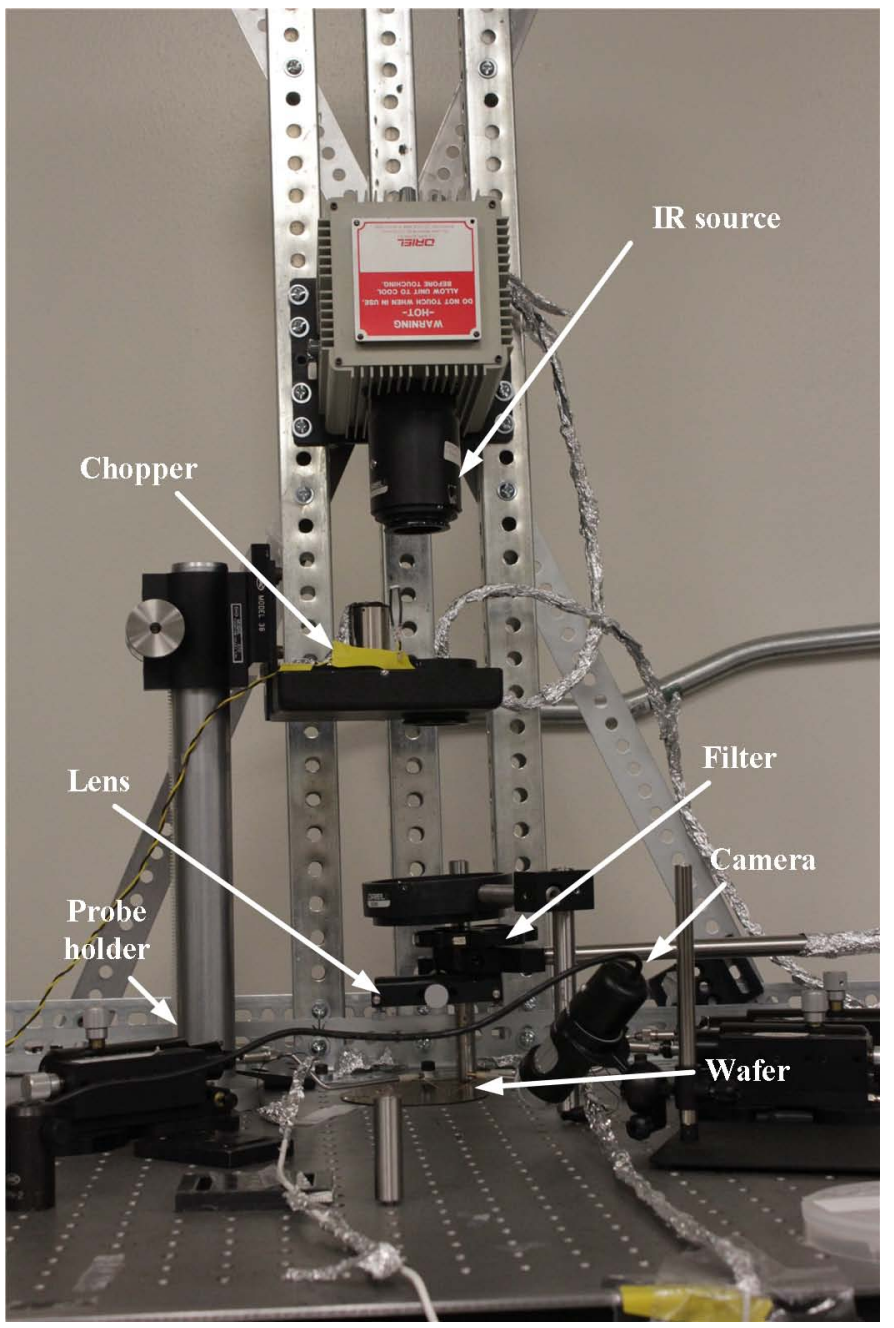


Figure 8

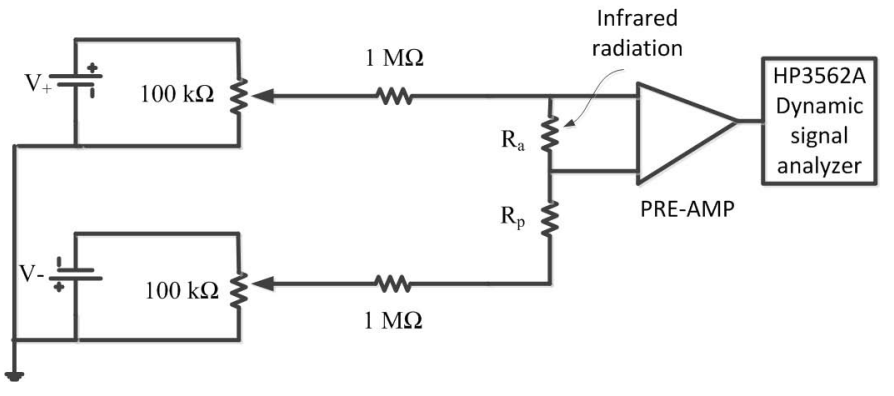




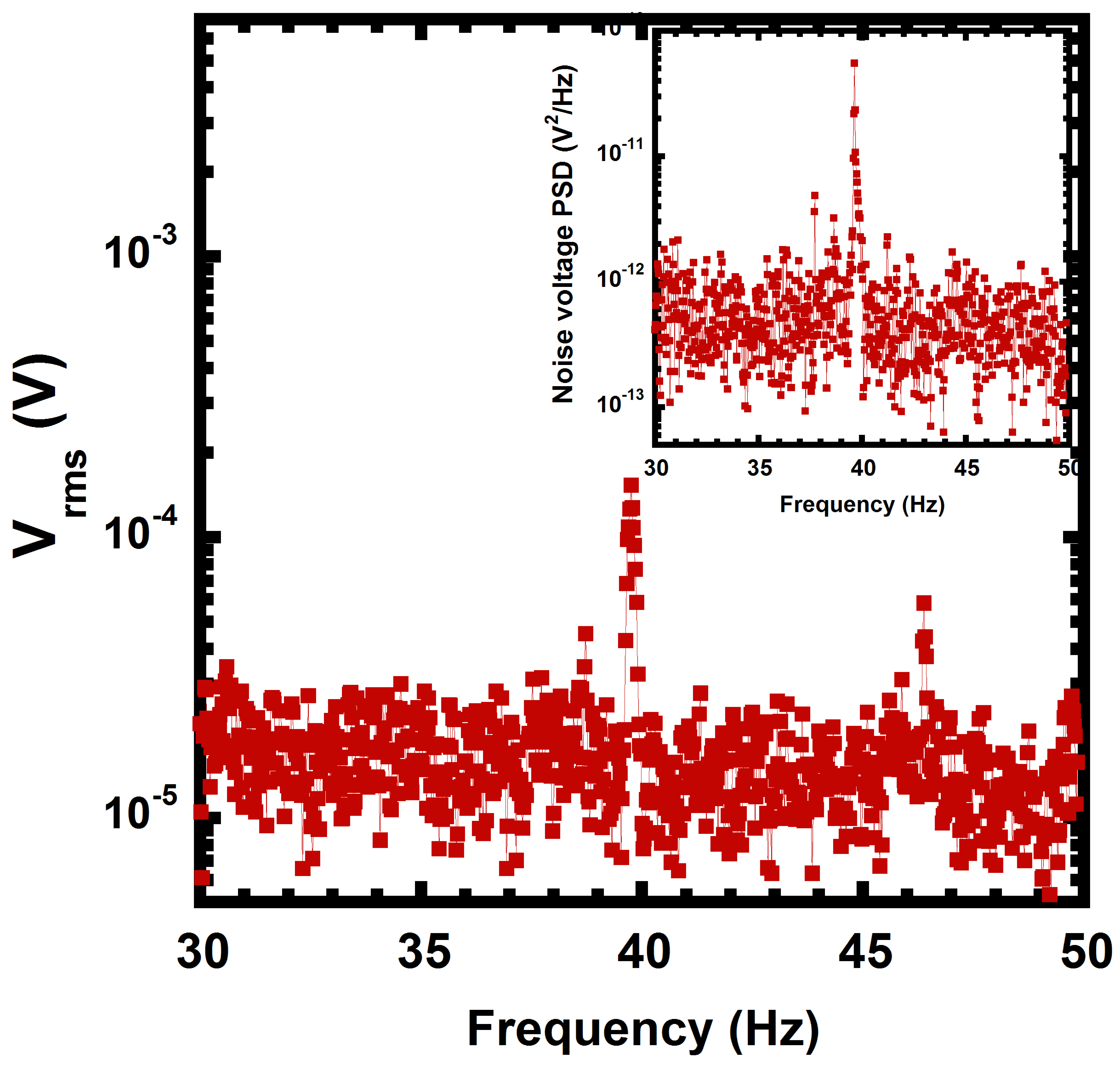




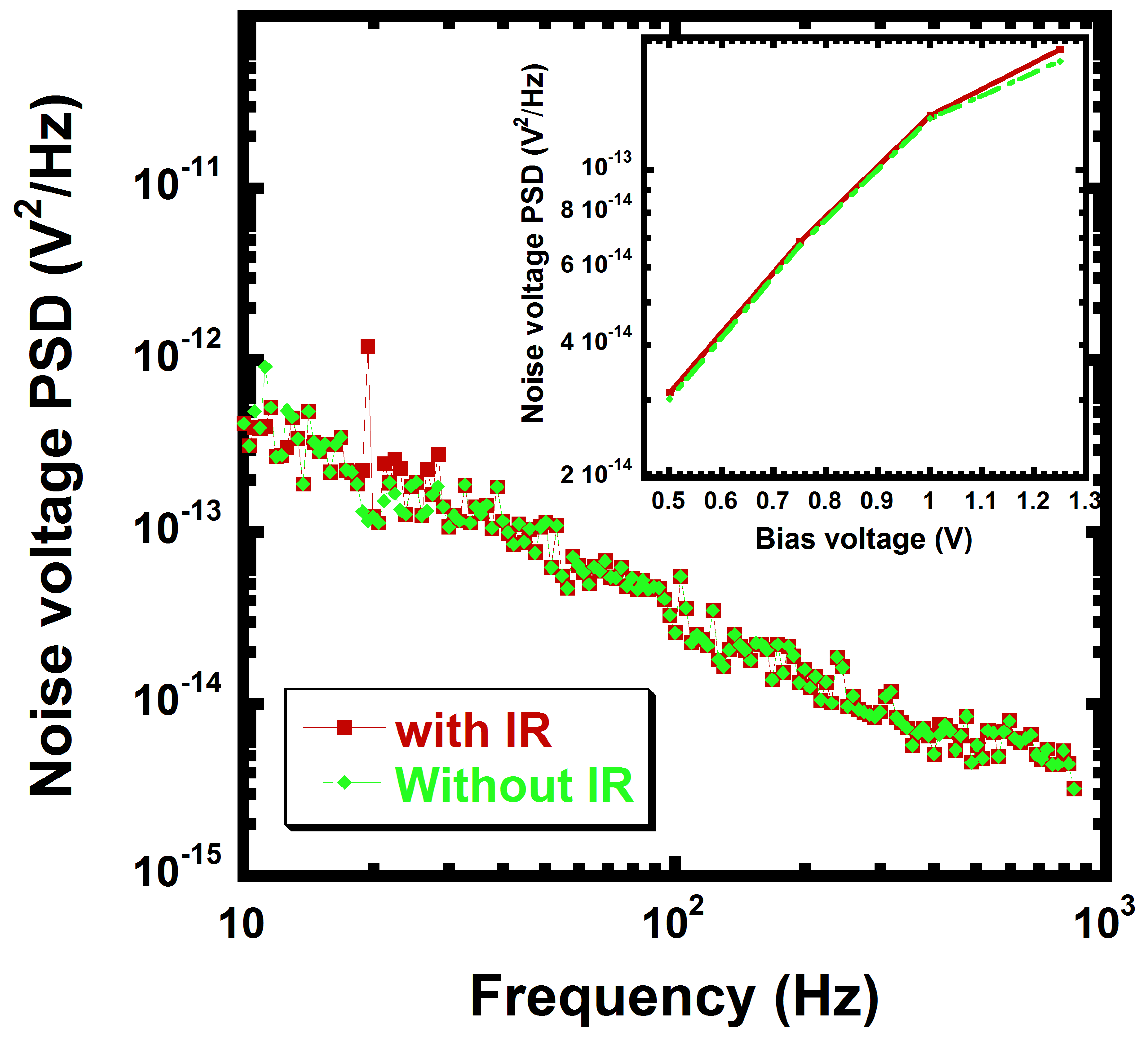




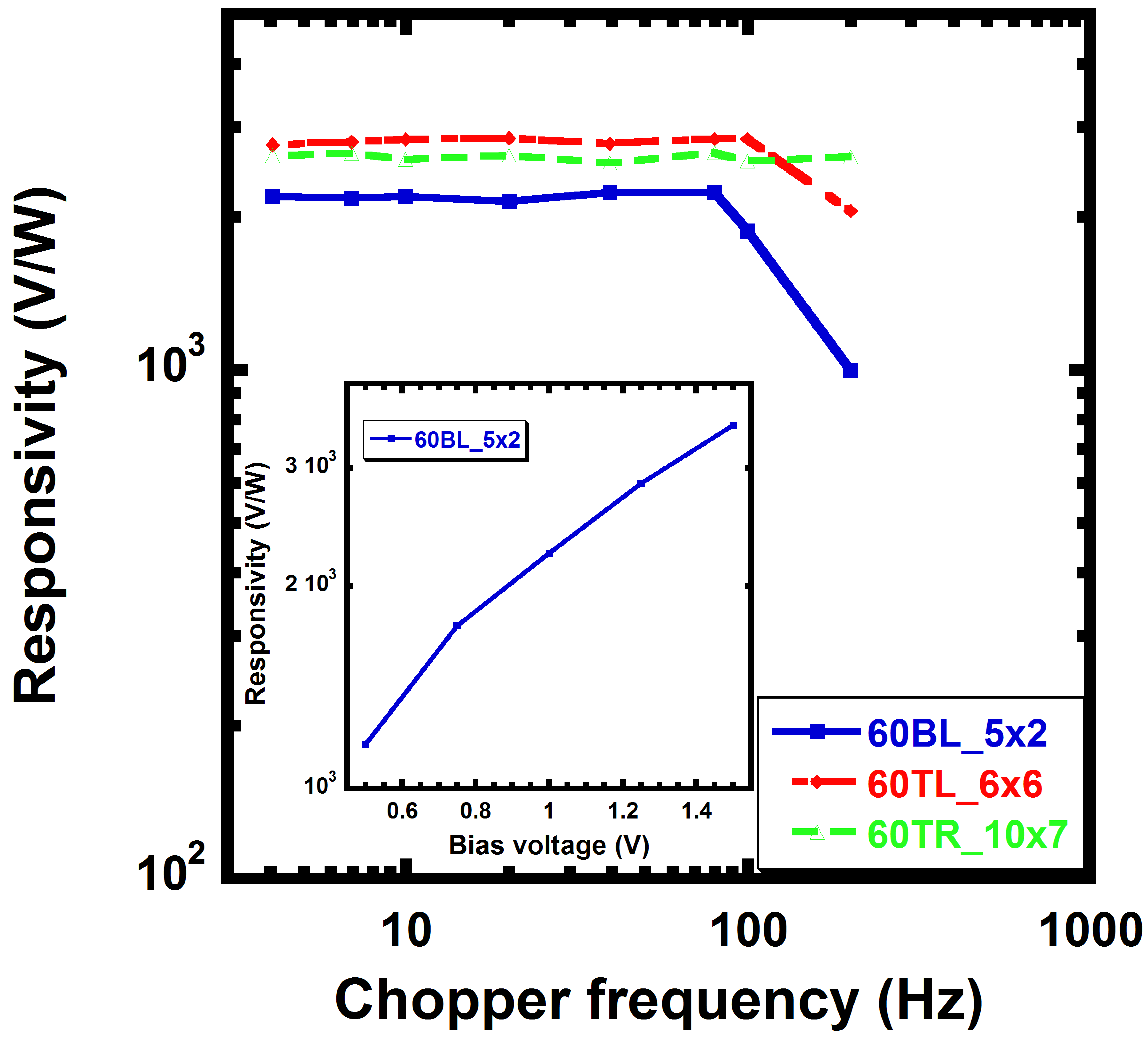




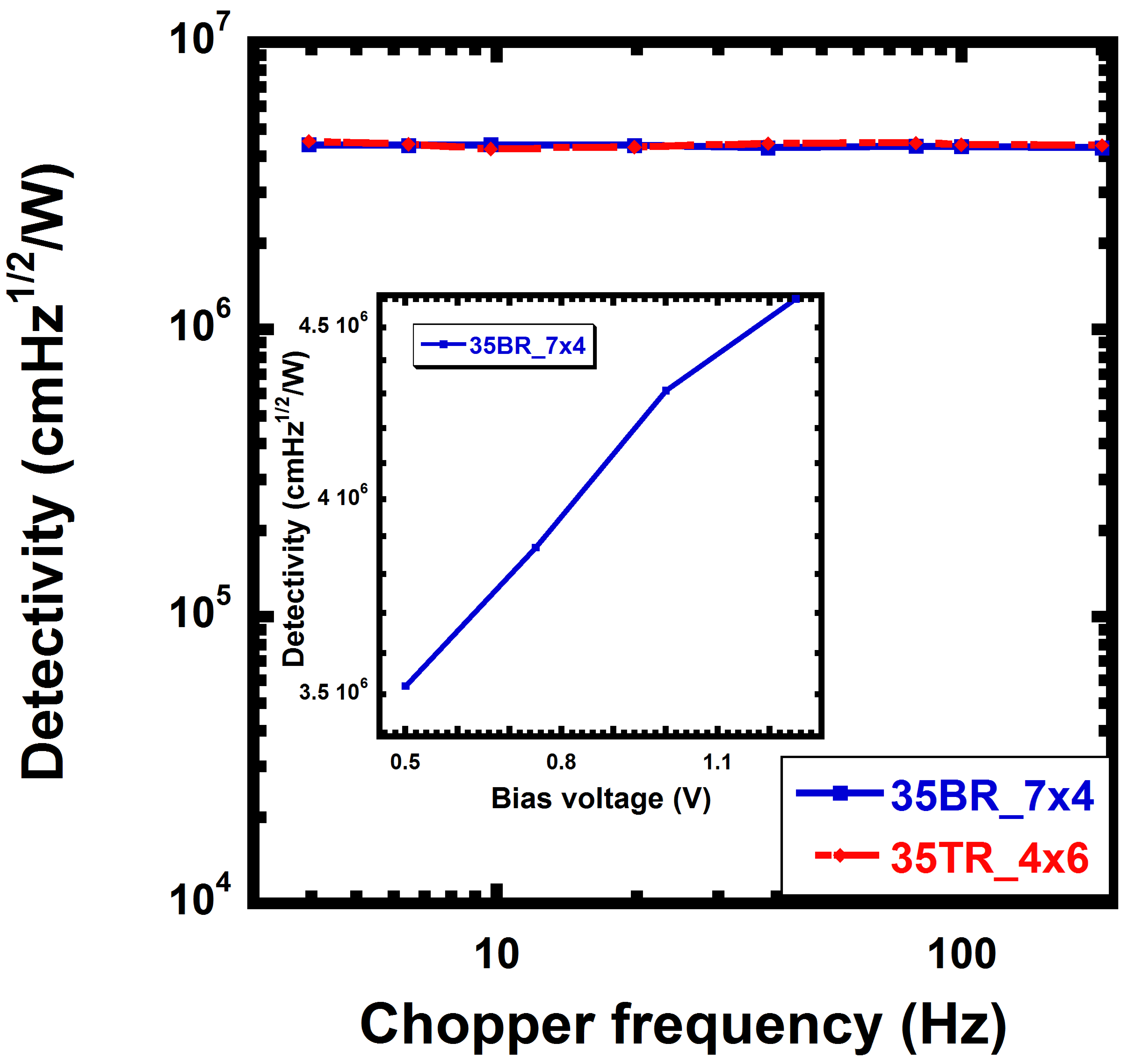




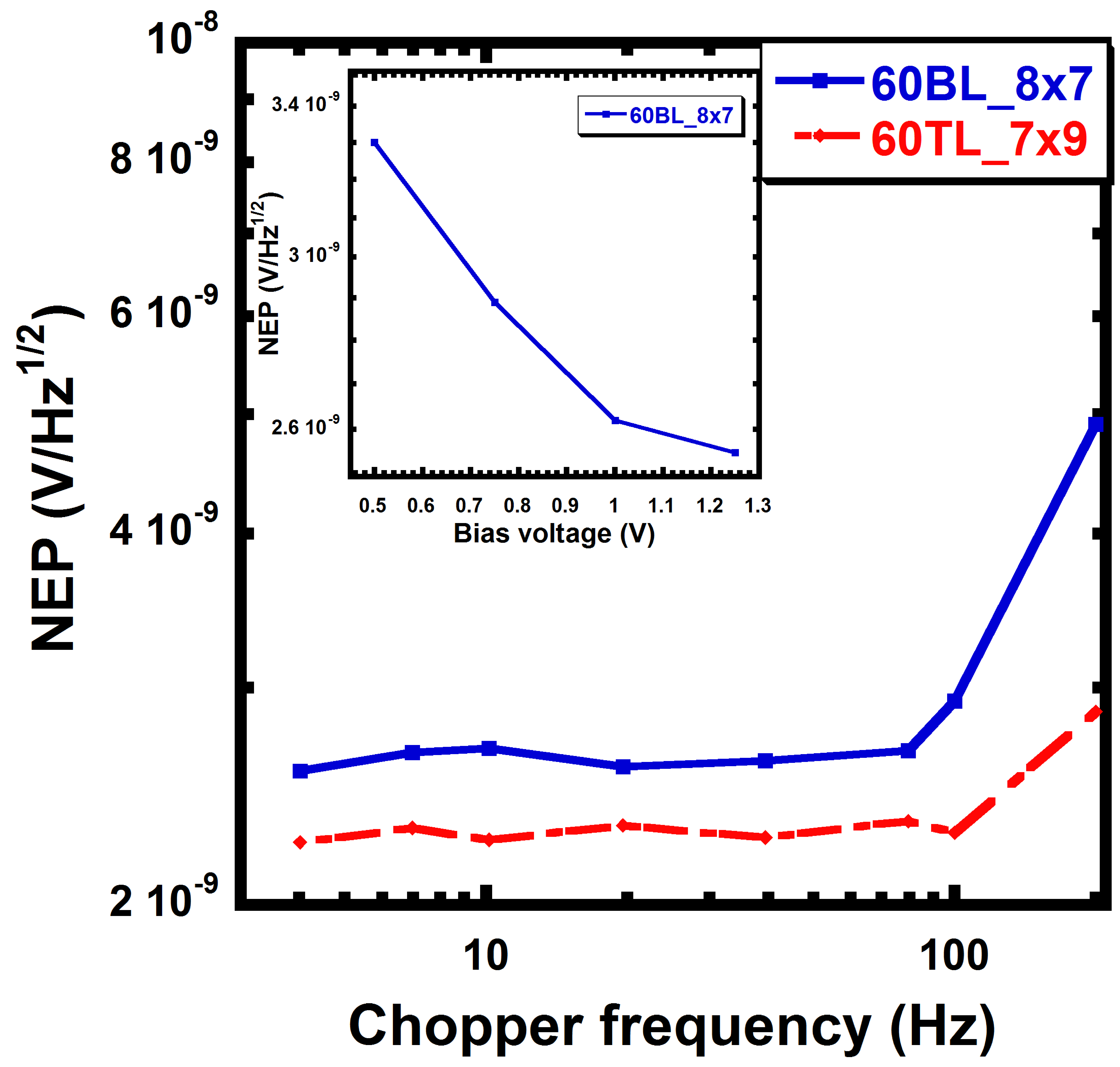


TABLE 1: Summary of the characteristics of the bolometers

\begin{tabular}{|c|c|c|c|c|c|c|c|c|c|c|}
\hline $\begin{array}{l}\text { Detector } \\
\text { name }\end{array}$ & $\begin{array}{c}\text { Pixel size } \\
\left({ }^{*} \mu \mathrm{m} \times\right. \\
\left.{ }^{*} \mu \mathrm{m}\right)\end{array}$ & $\begin{array}{c}\text { Leg } \\
\text { length } \\
(\mu \mathrm{m})\end{array}$ & $\begin{array}{l}\text { Active } \\
\text { resisto } \\
\mathrm{r}(\mathrm{G} \Omega)\end{array}$ & $\begin{array}{l}\text { Passiv } \\
\mathrm{e} \\
\text { resisto } \\
\mathrm{r}(\mathrm{G} \Omega)\end{array}$ & $\begin{array}{c}\text { Hooge } \\
\text { coefficie } \\
\text { nt }\end{array}$ & $\begin{array}{l}\text { Simulated } \\
\text { thermal } \\
\text { conductanc } \\
\text { e }(\mathrm{W} / \mathrm{K})\end{array}$ & $\begin{array}{l}\text { Simulate } \\
\text { d cut-off } \\
\text { frequenc } \\
\text { y }(\mathrm{Hz})\end{array}$ & $\begin{array}{l}\text { Responsivit } \\
\mathrm{y} \text { at } \pm 1 \mathrm{~V} \\
\text { and } 40 \mathrm{~Hz} \\
(\mathrm{~V} / \mathrm{W})\end{array}$ & $\begin{array}{l}\text { Detectivity } \\
\text { at } \pm 1 \mathrm{~V} \text { and } \\
40 \mathrm{~Hz} \\
\left(\mathrm{cmHz}^{1 / 2} / \mathrm{W}\right.\end{array}$ & $\begin{array}{l}\text { NEP at } \pm 1 \mathrm{~V} \\
\text { and } 40 \mathrm{~Hz} \\
\left(\mathrm{~V} / \mathrm{Hz}^{1 / 2}\right)\end{array}$ \\
\hline $\begin{array}{c}\text { 35BR_7x } \\
4\end{array}$ & $35 \times 35$ & 75 & 90 & 4 & $\begin{array}{r}3.94 \times 10^{-} \\
13\end{array}$ & $2.89 \times 10^{-7}$ & 238 & $3.71 \times 10^{3}$ & $4.31 \times 10^{6}$ & $8.12 \times 10^{-10}$ \\
\hline$\underset{6}{35 T R \_4 x}$ & $35 \times 35$ & 20 & 500 & 200 & $\begin{array}{r}4.09 \times 10^{-} \\
13\end{array}$ & $8.67 \times 10^{-7}$ & 909 & $3.78 \times 10^{3}$ & $4.44 \times 10^{6}$ & $7.88 \times 10^{-10}$ \\
\hline $\begin{array}{c}\text { 60BL_5x } \\
2\end{array}$ & $60 \times 60$ & 75 & 100 & 1.00 & $1.78 \times 10^{-}$ & $3.13 \times 10^{-7}$ & 86.35 & $2.24 \times 10^{3}$ & $2.08 \times 10^{6}$ & $2.89 \times 10^{-9}$ \\
\hline $\begin{array}{c}\text { 60BL_8x } \\
7\end{array}$ & $60 \times 60$ & 75 & 20 & 20 & $\begin{array}{r}1.29 \times 10^{-} \\
13\end{array}$ & $3.13 \times 10^{-7}$ & 86.35 & $2.58 \times 10^{3}$ & $2.29 \times 10^{6}$ & $2.62 \times 10^{-9}$ \\
\hline $\begin{array}{c}60 \mathrm{TL} \_6 \mathrm{x} \\
6\end{array}$ & $60 \times 60$ & 50 & 200 & 100 & $1.10 \times 10^{-}$ & $4.03 \times 10^{-7}$ & 113.25 & $2.79 \times 10^{3}$ & $2.25 \times 10^{6}$ & $2.66 \times 10^{-9}$ \\
\hline $\begin{array}{c}60 \mathrm{TL} \_7 \mathrm{x} \\
9\end{array}$ & $60 \times 60$ & 50 & 90 & 1 & $\begin{array}{r}1.25 \times 10^{-} \\
13\end{array}$ & $4.03 \times 10^{-7}$ & 113.25 & $2.89 \times 10^{3}$ & $2.64 \times 10^{6}$ & $2.27 \times 10^{-9}$ \\
\hline $\begin{array}{c}\text { 60TR_10 } \\
\times 7\end{array}$ & $60 \times 60$ & 20 & 0.4 & 0.2 & $1.20 \times 10^{-}$ & $10.1 \times 10^{-7}$ & 309.6 & $2.56 \times 10^{3}$ & $2.15 \times 10^{6}$ & $2.79 \times 10^{-9}$ \\
\hline
\end{tabular}


Table 2: Comparison of figures of merit

\begin{tabular}{|c|c|c|c|c|c|}
\hline Reference & $\begin{array}{c}\text { Device- } \\
\text { level } \\
\text { long- } \\
\text { pass } \\
\text { optical } \\
\text { filter }\end{array}$ & $\begin{array}{c}\text { Detecting } \\
\text { material }\end{array}$ & $\begin{array}{c}\text { Maximum } \\
\text { Detectivity } \\
\left(\mathrm{cmHz}^{1 / 2} / \mathrm{W}\right)\end{array}$ & $\begin{array}{c}\mathrm{NEP} \\
(\mathrm{V} / \\
\left.\mathrm{Hz}^{1 / 2}\right)\end{array}$ & $\begin{array}{c}\text { Biasing } \\
\text { power }\end{array}$ \\
\hline $\begin{array}{c}\text { Current } \\
\text { work }\end{array}$ & Yes & $\mathrm{a}-\mathrm{Si}$ & $\begin{array}{c}4.54 \times 10^{6} \\
\text { at } 4 \mathrm{~Hz}\end{array}$ & $\begin{array}{c}7.72 \\
\times 10^{-} \\
10\end{array}$ & $\begin{array}{c}5.71 \\
\mathrm{pW}\end{array}$ \\
& & & & $\begin{array}{l}\text { at } 4 \\
\mathrm{~Hz}\end{array}$ & \\
\hline $\begin{array}{c}\text { Mahmood } \\
\text { et al. } \\
\text { [Error! } \\
\text { Bookmark } \\
\text { not } \\
\text { defined.] }\end{array}$ & No & YBCO & $5.2 \times 10^{5}$ & $7.1 \times$ & 597 \\
at $398 \mathrm{~Hz}$ & $10^{-7}$ \\
at 5 & $\mathrm{nW}$ \\
\hline $\begin{array}{c}\text { Dayeh } e t \\
\text { al. } \\
\text { [Error! } \\
\text { Bookmark } \\
\text { not } \\
\text { defined.] }\end{array}$ & No & YBCO & $1.1 \times 10^{8}$ & $1.1 \times$ & 3.29 \\
$\mathrm{~Hz}$ & & \\
\hline
\end{tabular}

